\title{
REPENSANDO O CONSUMO EM TEMPOS DE MODERNIDADE LÍQUIDA: CONSTRUINDO SOCIEDADES MAIS SUSTENTÁVEIS NO CENÁRIO PÓS PANDEMIA
}

\author{
Tainá Silva Candido Toscan ${ }^{1}$ \\ Guilherme Fernandes Toscan²
}

Resumo: o presente estudo objetivou ponderar sobre como construir sociedades sustentáveis a partir da reflexão sobre a sociedade do consumo em tempos de modernidade líquida, bem como, o impacto do atual modelo produtivista na natureza a partir da produção massiva de bens de consumo. Dentre as atividades suspensas no atual cenário de pandemia, acentuamos o comércio, e, por conseguinte, o consumismo exacerbado. Partindo dessa ótica, propomos alternativas sustentáveis para reger essa orquestra desafinada que persiste em negação diante dos sintomas tangíveis do insucesso ao tentar promover satisfação humana por meio exclusivo do estímulo ao consumo, além de levantar algumas questões para futuras pesquisas.

Palavras-chave: Sustentabilidade; Alternativas Sustentáveis; Educação Ambiental; Consumismo; Modernidade Líquida.

Abstract: the present study aimed to ponder how to build sustainable societies from the reflection on the consumer society in times of liquid modernity, as well as the impact of the current productivist model on nature from the mass production of consumer goods. Among the activities suspended in the current pandemic scenario, we accentuate trade, and, therefore, exacerbated consumerism. From this perspective, we propose sustainable alternatives to conduct this out-of-tune orchestra that remains in denial in the face of the tangible symptoms of failure when trying to promote human satisfaction through the exclusive encouragement of consumption, in addition to raising some questions for future research.

Keywords: Sustainability; Sustainable Alternatives; Environmental Education; Consumerism; Liquid Modernity

Universidade do Extremo Sul Catarinense. E-mail: tainacandido1@hotmail.com,

Link para o Lattes: http://lattes.cnpq.br/1182687082656211

2 Universidade do Extremo Sul Catarinense. E-mail: guift83@hotmail.com

Revbea, São Paulo, V. 15, № 4: 190-204, 2020. 


\section{Introdução}

Considerando o atual cenário mundial, em que o Planeta Terra sofre de forma acentuada as consequências desde o período da industrialização, do desenvolvimento tecnológico acelerado e, por conseguinte, da globalização, há que se ter em vista a emergência da reflexão e questionamento do paradigma vigente, marcado pela lógica hegemônica do capital, visão antropocêntrica, mercadológica e insustentável. Reflexão essa, que, sobretudo, pressupõe o desenvolvimento de uma consciência crítica e autocrítica sobre a complexidade que envolve as questões socioambientais.

Os apontamentos de Bauman (2001), ao diferenciar a modernidade sólida da modernidade líquida, são oportunos no presente artigo. Diferenciando os modos como as vidas humanas convivem na sociedade, o autor oferece razões factíveis para se pensar alternativas ao modelo de sociedade vigente, o que pretendemos fazer.

O que Bauman (2001) chama de sociedade líquida é caracterizado pela incapacidade de manter a forma, devido sua fluidez, mobilidade. Diferentemente nas sociedades sólidas, nossos estilos de vida, crenças, instituições e convicções mudam rápido demais, sem tempo de se solidificar em costumes.

O discurso de liberdade, oriundo do derretimento das sociedades sólidas, que eram éticas, compreensivas e duradouras, não passa de ilusão levando-nos a um oceano de incertezas, que "apenas transformou o indivíduo de cidadão político em consumidor de mercado" (BAUMAN, 2000, p. 84). Portanto, não mais éticas, as comunidades são estéticas e se reúnem em torno do entretenimento e das relações transitórias, com laços afetivos cada vez mais fracos.

Além disso, os riscos da pós-modernidade são mais sutis do que se pode imaginar, afinal, mesmo expostos, não podemos cheirar, tocar, ver, ouvir as condições climáticas, mas que estão se deteriorando gradativamente e sem tréguas. Essa sutileza também pode ser exemplificada nas questões relacionadas aos níveis de radiação, poluição, diminuição das matérias primas não-renováveis, globalização sem controle político e ético, que cada vez mais impactam nas bases de nossa existência (PALLARES-BURKE, 2004). Esses riscos, mesmo quando notados, tendem a ser minimizados, em outras palavras, camuflados.

Vivemos em tempos de modernização compulsiva, em que

movemo-nos e continuaremos a nos mover não tanto pelo adiamento da satisfação, mas por causa da impossibilidade de atingir a satisfação: o horizonte da satisfação, a linha de chegada do esforço e o momento da autocongratulação tranquila movem-se rápido demais. (BAUMAN, p. 41, 2001). 
Em tempos que ser moderno é ser incapaz de parar, de instantaneidade, tempo sem consequências, objetificação das relações, satisfação imediata, consumismo, egocentrismo e individualismo, a sociedade, finalmente, "parou". A pandemia de coronavírus (COVID-19), forçou o mundo a parar, e, possivelmente, repensar seus hábitos e costumes, dada a profundidade das fissuras na película social e abrupta frenagem da economia.

Nesse processo de medos e incertezas, muitas atividades que antes eram consideradas indispensáveis, foram coagidas a fechar, ao contrário de outras que foram elencadas como essenciais a fim de abrandar os efeitos dantescos da crise, revelando o que realmente é indispensável para a subsidência humana. $O$ resultado dessa parada imposta foi sentido negativamente na economia e positivamente no meio ambiente, afinal, a natureza respirou. Dentre as atividades suspensas, acentuamos o comércio, e, por conseguinte, o consumo. Nesse caso específico, trataremos do consumismo exacerbado.

Constatou-se, por meio de Araújo (2008), que a sociedade do consumo nos priva da reflexão e autocrítica e que a satisfação ilusória e momentânea ocorre em detrimento da consciência de responsabilidade, dificultando a compreensão da totalidade. Agora, diante da pausa, julgamos ser ainda mais necessária a reflexão e discussão sobre a imprescindibilidade de uma nova maneira de ver e viver nossas relações com o Planeta e com o próprio ser humano na era da modernidade líquida, pensando novas formas de ser e estar no mundo. Afinal, aquilo que comprávamos quanto realmente precisávamos?

Nessa lógica, devemos pensar em alternativas sustentáveis para reger essa orquestra desafinada que persiste em negação diante dos sintomas tangíveis do insucesso ao tentar promover satisfação humana por meio exclusivo do estímulo ao consumo. Torna-se, portanto, impossível continuar a presente narrativa sem mencionar a leviandade do atual sistema capitalista, promotor de uma visão antropocêntrica e competitiva, em detrimento de um sistema sustentável e socialmente justo de desenvolvimento.

A reflexão sobre os impactos do sistema vigente na humanidade/natureza e da necessidade de se pensar em alternativas contrárias, traz consigo questões relacionadas aos bens intangíveis e não negociáveis, que, comumente também são apropriados pelo mercado, afinal, na sociedade capitalista, a busca pela felicidade de uma vida plena e satisfatória é atrelada ao consumo de mercadorias (BAUMAN, 2009).

A pertinência do tema é significativa ao evidenciarmos, por meio da mídia, reportagens como a de Melo (2020), que constatou mudanças em nossa vida devido ao coronavírus e as tendências para o mundo pós-pandemia. De acordo com o autor da matéria, a COVID-19 vai rever valores e mudar alguns hábitos da sociedade, como, por exemplo: "consumir por consumir sai de moda, morar perto do trabalho, atuar mais no coletivo com colegas de empresas, ou vizinhos do bairro". Melo (2020) argumenta que o mundo póspandemia será diferente e que o coronavírus antecipou mudanças que já 
estavam em curso, dentre elas a busca por sustentabilidade. Além das mudanças destacadas, está o fortalecimento de valores, como a solidariedade e a empatia e a reflexão sobre 0 modelo de sociedade baseado no consumismo e lucro.

Mediante o exposto, o presente estudo objetivou refletir sobre a sociedade do consumo em tempos de modernidade líquida, bem como, 0 impacto do atual modelo produtivista na natureza a partir da produção massiva de objetos artificiais sob pretensas e falsas necessidades também produzidas artificialmente. Nesse contexto de pandemia, propomos alternativas para se pensar uma sociedade mais justa e sustentável, além de levantar algumas questões para futuras pesquisas.

\section{A sociedade do consumo no contexto da COVID-19: à guisa de alternativas sustentáveis}

A dialética entre homem e meio ambiente natural foi exposta como nunca havia sido em tempos modernos. A relação profundamente desgastada entre esses dois atores parece ter chegado a um clímax, em que se torna evidente o desequilíbrio causado pela insistente imposição humana frente aos limites naturais que permeiam e regem o Planeta Terra. No contexto de pandemia de coronavírus, o desenvolvimento vertical do consumo foi comprometido juntamente com as mazelas sociais, em tempos em que as interrelações humanas estão limitadas a quatro paredes e o consumo de alguns produtos, outrora vistos como necessários, relegado a segundo plano.

Nesse sádico cenário global, a exposição da fragilidade social tomou voz, acentuando a desigualdade causada pelo sistema econômico em voga, que prioriza o mercado de capital em detrimento da saúde e necessidades básicas de sobrevivência das classes trabalhadoras. Seria, de tal modo, inverossímil, pensar em uma sociedade voltada ao conceito do consumo consciente, bem como, com pensamentos e ações norteadoras para um desenvolvimento sustentável que prioriza os reais valores humanos, sem ferir a hegemonia natural do Planeta?

É preciso pensar de forma responsiva para avaliar e responder tal questionamento. Pisamos em um campo minado. O poder de consumo, atualmente abalado pela inexistência e irrelevância de seu mecanismo pulsante, que podemos aqui definir como vitrine sem ninguém para apreciar, expôs as entranhas de uma sociedade amplamente amparada pela distinção do ter em detrimento do ser. Tal situação exprime certa lacuna no mecanismo do capital, porém, não limita sua prevalência sobre o cenário pós-pandemia, em que os meios de consumo serão vertiginosamente incentivados a fim de que ocorra recuperação econômica satisfatória.

Está claro para a população, por meio de vários discursos científicos e até mesmo empiricamente, que o modelo de desenvolvimento no qual o mundo se alicerça está fadado ao fracasso. Modelo este que promove o que, em nossa opinião, poderia continuar suspenso, o consumismo desenfreado. Tal 
consumismo é altamente estimulado por meios de comunicação, que transformam produtos superficiais em bens de consumo indispensáveis através de propagandas bem elaboradas a fim de ludibriar e induzir os indivíduos.

Assim, nesse tempo de interrupção temporária do consumo, ou melhor, redução temporária do consumo, em função da COVID-19, pode-se citar, dentre outras, como atividade desnecessária, as agências de publicidade. Esse ramo de atividade se utiliza de inúmeros recursos apelativos (visuais, sonoros, entre outros) para convencer os indivíduos ao consumo. Para Lowy (2015, p. 83), a publicidade é um "desperdício monumental de energia humana, trabalho, papel, árvores destruídas para gasto de papel, eletricidade etc., e tudo isso para convencer o consumidor de que o sabonete $X$ é melhor do que o sabonete Y..."

A publicidade, nesse ciclo, ou como Latouche (2009) denomina, "ronda diabólica", é um dos elementos necessários para que a sociedade do consumo possa progredir, tendo como função criar o desejo de consumir, nos fazendo "desejar o que não temos e desprezar aquilo que já desfrutamos" (LATOUCHE, 2009, p. 18). É um interminável processo de insatisfação e desejos frustrados por bens de alta futilidade.

Poderíamos nos dedicar a escrever um único artigo sobre as agências de publicidade diante do tamanho de sua importância na modernidade líquida. Mas destacamos apenas alguns elementos que merecem nossa atenção, isso porque, a publicidade constitui o segundo maior orçamento mundial, ficando atrás somente da indústria de armamentos. Segundo pesquisa apontada por Latouche (2009), 90\% das maiores empresas americanas reconhecem que seria impossível vender um produto novo sem campanha publicitária. Dados que confirmam a publicidade como "elemento essencial do círculo vicioso e suicida do crescimento sem limites" (LATOUCHE, 2009, p. 18).

Além disso, tal sistema, baseado no consumo, opera na contramão da realidade e dos sintomas ambientais a muito deflagrados no seio do Planeta Terra. A extração incansável de recursos naturais não renováveis para a produção de bens de consumo, em suas grandes maiorias superficiais, declarou guerra ao equilíbrio natural. Daí somos direcionados ao sistema de obsolescência programada, que define a vida útil de um produto a partir de um interesse capital, a fim de incentivar o consumo e, simultaneamente, a insatisfação, em um ciclo infinito de compra e descarte. A obsolescência programada é a arma absoluta do consumismo, configurada em aparelhos produzidos a baixo custo pelo trabalho escravo do sudeste asiático que se tornam, em um curto período de tempo, inúteis (LATOUCHE, 2009). Tamanho é seu dano que,

montanhas de computadores se juntam a televisores, geladeiras, lava-louças, leitores de DVD e telefones celulares abarrotando lixos e locais de descarte com diversos riscos de poluição: 150 milhões de computadores são transportados 
todos os anos para depósitos de sucata do Terceiro Mundo (500 navios por mês para a Nigéria!), apesar de conterem metais pesados e tóxicos (mercúrio, níquel, cádmio, arsênico e chumbo) (LATOUCHE, 2009, p. 22).

Vivemos em um período em que o ser humano produz mais resíduos do que a Terra pode suportar, uma vez que, sua capacidade de regeneração já não é suficiente para comportar a demanda. Nesse processo, há o claro desinteresse do atual sistema em incentivar a aquisição de produtos duráveis e que promovam a sustentabilidade, a curto, médio e longo prazo, como por exemplo, a geração de energia elétrica por meio do efeito fotovoltaico, que resolveria definitivamente, em locais de grande radiação solar, o déficit de fornecimento de energia, causado por uma matriz energética colapsada, e, beneficiaria, dentre outros, pessoas em vulnerabilidade social.

$\mathrm{Na}$ mesma lógica, o que dizer da alimentação amplamente oferecida? Consumimos produtos massivamente processados, ao ponto de não serem capazes de promover a mínima nutrição humana necessária, em detrimento de produtos saudáveis e orgânicos, que deveriam ter seus custos barateados, além de incentivos fiscais, tais como os vegetais orgânicos oriundos da policultura em substituição dos vegetais carregados de agrotóxicos produzidos em sistemas de monocultura, que além de impactarem o meio ambiente, contaminando e exaurindo o solo, trazem uma carga imensurável de produtos químicos tóxicos que afetam significativamente o organismo humano, promovendo, em muitos casos, o desenvolvimento de doenças, como câncer, além de inúmeros problemas psíquicos, como a depressão.

Nesse contexto, observamos os inúmeros efeitos colaterais, diretos e indiretos, do sistema capitalista de desenvolvimento. As pressões sociais, o poderio, ou não, de compra, os estigmas sociais, o desemprego, a degradação ambiental, as condições socioeconômicas e tantos outros fatores, que contribuem para evidenciar as mazelas de um sistema opressor.

Os efeitos são dantescos e se confirmam em estudos sobre a mortalidade por suicídio no Brasil, dentre eles, Gonçalves et al. (2011, p. 283) destacam as pesquisas de Shikida et al. (2006) e Meneghel et al. (2004), que, por meio de uma série de estudos e dados, analisaram de que forma as variáveis econômicas influenciavam nas taxas de suicídios nos estados brasileiros. Como exemplo, cita-se o estado do Rio Grande do Sul, onde se verificou a relação direta dos altos índices de morte auto-inflingida com precárias condições de sobrevivência, endividamento, concentrações de terra, êxodo e a exposição profissional intensa de trabalhadores rurais aos agrotóxicos, que, nesse contexto, são absorvidos por meio da aplicação maciça no cultivo de sistemas de monocultura.

Além disso, muitos bens considerados intangíveis e não negociáveis também são apropriados pelo mercado de mercadorias, o que faz com que na 
sociedade capitalista, a busca pela felicidade de uma vida plena e satisfatória é atrelada ao consumo de mercadorias (BAUMAN, 2009). Nas palavras do autor,

uma vez que os bens capazes de tornar a vida mais feliz começam a se afastar dos domínios não-monetários para o mercado de mercadorias, não há como os deter; o movimento tende a desenvolver um impulso próprio e se torna autopropulsor e autoacelerador, reduzindo ainda mais 0 suprimento de bens que, pela sua natureza, só podem ser produzidos pessoalmente e só podem florescer em ambientes de relações humanas intensas e íntimas (BAUMAN, 2009, p. 16).

A produção desenfreada e insustentável de bens de consumo, como vimos, não só afeta as relações da humanidade com a natureza, como também as relações entre a própria humanidade. Por essa razão, a análise do impacto do sistema produtivista também envolve questões políticas e sociais. O ter, nesse contexto, é uma questão de adquirir e manter uma posição social, que nada significa a menos que "tenha sido socialmente reconhecida - ou seja, a menos que a pessoa em questão seja aprovada pelo tipo certo de 'sociedade' (cada categoria de posição social tem seus próprios códigos jurídicos e seus próprios juízes) como um membro digno e legítimo - como 'um de nós'” (BAUMAN, 2009, p. 21).

Nesse cenário, o consumismo não só está produzindo desastres ambientais irreparáveis, como também, promove e consolida o individualismo, a desigualdade e injustiça social. Assim sendo, repensar a sociedade do consumo requer o desenvolvimento de racionalidades críticas e autocríticas, sobretudo considerando as questões socioambientais e os impactos das relações sobre o Planeta e os seres humanos, tendo em vista que o atual modelo desenvolvimentista e de cunho neoliberal é o grande responsável pela degradação ambiental e humana.

A nossa atenção ao modelo em voga é devido ao fato de que o consumo se configura em estratégia bem pensada em que o capitalismo ganha consentimento através da falsa sensação de conforto e liberdade, instigando a busca por um padrão de vida em ascensão e encobrindo "o antagonismo de classe entre explorados e exploradores - e pode até mesmo encorajar uma sensação de dívida/gratidão dos explorados para com os exploradores quando estes promovem melhorias de vida pontuais" (FERNANDES, 2019, p. 48).

O pensamento acima vai ao encontro do que Bauman (2000) aponta como falsa liberdade. No contexto do discurso da liberdade, a "classe trabalhadora se encontra em uma posição fatalista cultural e materialista devido à ilusão de progresso no crescimento da capacidade produtiva (e potencial de consumo)" (FERNANDES, 2019, p.48). A falsa liberdade também se configura em crédito que, por sua vez, fornece os meios para atingir os bens de consumo (LATOUCHE, 2009). É por essas e outras razões que apontamos a 
necessidade da discussão em torno das questões sociais, econômicas, políticas e ambientais, afinal, as mudanças ambientais são decorrentes das relações sociais.

Dentre as alternativas sustentáveis em resposta à crise civilizatória oriunda do modelo capitalista, consideramos pertinente a concepção do Bem Viver, que questiona narrativas da modernidade e o modelo capitalista visto como única forma possível de pensar e viver.

A perspectiva do Bem Viver vai ao encontro da nossa intenção de repensar a sociedade do consumo, uma vez que, é necessário colocar em pauta o desenvolvimento baseado no crescimento exponencial de bens e serviços, que supõe a exploração ilimitada dos recursos naturais e humanos. Além disso, sabemos que a distribuição dos frutos desse desenvolvimento não é de igual modo para todos.

Vale acentuar que, pensar no Bem Viver como proposta alternativa para um desenvolvimento sustentável não é tarefa simples em um contexto em que o modelo vigente tende a ignorar propostas que vão de encontro com seus princípios, isto é, "fora do cânon ocidental de formação da modernidade e do capitalismo como projeto civilizatório" (CUADRA, 2015, p. 1). No entanto, entendemos a importância do projeto de base e a pertinência, considerando o atual cenário em que nos encontramos, do que nos propusemos a fazer.

Segundo Cuadra (2015, p. 2), não só estamos esgotando os recursos naturais e promovendo a crise climática, como estamos acentuando a desigualdade social e exploração humana. A crise não é só ambiental, é crise da razão, crise civilizatória. Portanto, como bem coloca o autor, "se a humanidade não mudar seu estilo de desenvolvimento, em menos de um século colocaremos em sério risco a sobrevivência do planeta e do gênero humano".

Conforme Cuadra (2015), o Bem Viver questiona justamente esse padrão produtivista e consumista considerado base rumo ao progresso. Nessa perspectiva, diferentemente do incentivo à produção e acúmulo de maiores quantidades possíveis de riquezas, o Bem Viver propõe o equilíbrio entre as reais necessidades humanas e os recursos disponíveis para satisfazê-las. Essa lógica parte da cosmovisão oriunda dos povos originários, estes, com suas epistemologias negligenciadas e excluídas até então.

Partindo do princípio de totalidade, o Bem Viver pressupõe uma visão planetária em que os seres humanos formam parte de um todo, sobretudo, de forma harmônica com os outros seres humanos e com a natureza. Não há uma fórmula mágica, mas sim a necessidade do desenvolvimento da consciência crítica, planetária, ambiental, rumo a essa proposta que, segundo Cuadra (2015), está em construção permanente, considerando a diversidade cultural e pluralidade que se enriquece permanentemente na convivência cotidiana, sob o entendimento de que há diferentes, mas não menos importantes, conhecimentos e formas de viver. 
Portanto, indo na contramão da lógica no modelo devastador capitalista, estamos propondo, como forma de superação gradativa do mesmo, uma lógica centrada na cooperação. Cooperação é a base para desestruturar um sistema totalmente individualista, egocêntrico e desigual. Isso só será possível na medida em que temos consciência de interdependência, superando a visão tradicional de desenvolvimento.

Tendo em vista o exposto, diversas outras correntes propuseram-se a pensar em propostas alternativas, que após experimentos, se mostraram possíveis. Dentre elas, mencionamos sucintamente a perspectiva de Marcel Mauss sobre o espírito de dom. Partindo do ciclo dar-receber-retribuir, seus estudos mostraram a capacidade de circuito de reciprocidade também no sistema econômico capitalista. Nesse caso, a perspectiva busca questionar o utilitarismo do ocidentalismo como única alternativa de troca, "aqui os bens que participam na permuta, possuem principalmente um valor simbólico, valor de uso marcado pelas relações que surgem e se estabelecem em função desse bem" (CUADRA, 2015, p. 5).

Há também, dentre as alternativas pensadas que vão de encontro ao modelo produtivista, o conceito de decrescimento, bastante difundido na teoria de Serge Latouche, que também fez parte do movimento de Mauss. Sua perspectiva denuncia a ideia de crescimento ilimitado com objetivo exclusivamente de obtenção de lucro sem considerar as consequências desastrosas para o meio ambiente e a própria humanidade. Nesse caso, o decrescimento supõe, conforme Cuadra (2015, p. 5), a reorganização de nossas vidas, "através de formas mais conscientes de consumo e por meio de uma vida mais simples, sem grandes parafernálias que nos cercam, utilizando estritamente o que necessitamos para levar uma vida digna e plena".

Nas palavras do próprio autor e propulsor do movimento, a palavra decrescimento tem como principal meta "enfatizar fortemente o abandono do objetivo do crescimento ilimitado, objetivo cujo motor não é senão a busca do lucro por parte dos detentores do capital' (LATOUCHE, 2009, p. 4). O ser humano, nesse processo, é tido como objeto, instrumento ou meio da mecânica produtiva.

Vale destacar que, assim como Latouche (2009, p. 6), não estamos propondo a simples diminuição do crescimento e o aumento, por conseguinte, das taxas de desemprego, trata-se da mudança de uma sociedade passa a pensar baseada em outra lógica, "trata-se de rejeitar o culto irracional e quase idólatra do crescimento pelo crescimento". É, portanto, a crítica ao desenvolvimento, que questiona a dinâmica da acumulação capitalista e a necessidade de redução do consumo por autolimitação. É a descolonização de nosso imaginário. Afinal, "haverá realmente quem acredite que um crescimento infinito é possível num planeta finito?' (LATOUCHE, 2009, p. 23).

Latouche (2009) definiu oito mudanças necessárias para pensar a sociedade autônoma do decrescimento, são mudanças interdependentes, que, quando articuladas se reforçam. Consideramos pertinente a abordagem das 
sugestões propostas pelo autor, uma vez que se configuram em elementos palpáveis quando o objetivo é uma alternativa mais sustentável em oposição ao modelo vigente. Dentre elas, destacamos o que chama de reavaliar, que significa reavaliarmos nossos valores ou ausência deles, repensando questões como: altruísmo x egoísmo, cooperação x competição, prazer x lazer, vida social $x$ consumo ilimitado, local $x$ global, autonomia $x$ heteronomia, obras artísticas $\mathrm{x}$ eficiência produtivista, sensato $\mathrm{x}$ racional e relacional $\mathrm{x}$ material.

Por conseguinte, ao reavaliarmos nossos valores, iremos reconceituar conceitos considerados únicos e universais, proporcionando outra maneira de olhar o mundo e apreender a realidade (LATOUCHE, 2009). A palavra reestruturar também é proposta pelo autor, que considera fundamental a reestruturação do aparelho produtivista vigente, pensando em formas alternativas de organização. A reestruturação visa à redistribuição das riquezas e do acesso ao patrimônio natural. Conforme Latouche (2009, p. 47), a redistribuição terá impacto positivo no que tange a redução do consumo, "diretamente reduzindo o poder e os meios da classe consumidora mundial, indiretamente diminuindo a incitação ao consumo ostentatório".

Ainda sobre as sugestões propostas por Latouche (2009), está a de relocalizar, no sentido de produzir localmente os produtos essenciais para a satisfação das necessidades humanas. Isto é, a produção passa a ser local para as necessidades locais. Nesse contexto, o ideal é reduzir o impacto sobre o planeta através de nosso modo de produzir e consumir. Além disso, o autor menciona que não só essa redução é necessária, mas também a dos riscos sanitários e da carga horária dos trabalhadores.

$\mathrm{Na}$ mesma lógica, outra proposta que dialoga com os movimentos apresentados e que, para nós, é um movimento imprescindível e atual, é o ecossocialismo. O Ecossocialismo vai além de reformas e pautas da ecologia neoliberal, reducionistas, de consumo ou propagandistas em torno da reciclagem. O mesmo compreende uma ação profunda de reconstrução da relação entre o homem e os bens de produção. Assim, essa perspectiva, segundo Lowy (2015), diz respeito à crítica e a superação do modelo vigente, que não aceita alternativas, especificamente socialistas, e que não se relaciona com processo da luta de classes e não considera a questão da propriedade dos meios de produção.

Nesse ínterim, o ecossocialismo nos leva a uma profunda reflexão em torno da responsabilidade individual e coletiva, voltadas para a relação com o meio em que estamos inseridos. Nessa lógica, refutamos o individualismo e isolamento promovido pelo sistema atual de estímulo ao consumo desenfreado e voltamo-nos à política social que nos leva a coletividade de consumo, às cooperativas. Portanto, vai ao encontro do que Latouche (2009) chama de convivialidade, tão necessária quando se propõe o espírito de doação no comercio social e, por conseguinte, o resgate do laço social desfeito pelo poder econômico. 
Por essa razão, assim como Lowy (2015), defendemos a importância da reflexão crítica ao se pensar em propostas alternativas ou possíveis soluções à crise ambiental na qual vivenciamos. Conforme o autor, reflexão crítica para com a ecologia não socialista, isto é, a ecologia capitalista, que, por sua vez, não questiona o modelo produtivista e extrativista devastador. Portanto, o ecossocialismo surge, a partir de reflexão crítica, para irromper com esse modelo e com as tendências preservacionistas, instrutivas, que não superam significativamente o status quo, que não se relacionam com a luta de classes, não aceitam outras perspectivas e não colocam em questão os meios de produção.

A proposta ecossocialista não só pressupõe a reflexão crítica sobre o modelo capitalista e suas consequências, como também ao socialismo que não considera as questões ecológicas, como o socialismo implementado em determinados países, que, conforme Lowy (2015) se perderam em processos de burocratização e abraçaram a industrialização. Portanto, de nada adianta pensar propostas alternativas sem considerar a superação do modelo produtivista.

Nesse sentido, considerando a multidimensionalidade envolvendo as relações socioambientais, não é suficiente a transformação somente das relações de produção ou as relações de propriedade, mas a estrutura das forças produtivistas, do aparelho produtivo (LOWY, 2015), onde entra o ecossocialismo. Portanto, o aparelho produtivo deve ser, nesse contexto, transformado. Um dos exemplos de alteração no processo de produção é a substituição do uso de combustíveis fósseis pelas energias renováveis.

Portanto, o presente movimento vai além de reformas nas relações de produção e consumo, ao dialogar profundamente com o meio ambiente natural e colocar em pauta questões envolvendo a objetificação da natureza como algo descartável, instrumental, com finalidade exclusiva de suprir as necessidades capitais. Nesse sentido, na contramão do capitalismo, o ecossocialismo elege a relação homem e meio ambiente natural, como simbiose, em que há a interdependência entre ambos, o que naturalmente afeta toda a estrutura atual de produção, trabalho e consumo.

Entendemos que o ecossocialismo abrange as propostas voltadas para a perspectiva do Bem Viver, do decrescimento, dentre outras, que visam, além de transformar o modelo produtivo, um novo estilo de vida e mudanças no padrão de consumo, "baseado na satisfação das verdadeiras necessidades sociais, que é algo completamente diferente das pretensas e falsas necessidades produzidas artificialmente pela publicidade capitalista" (LOWY, 2015, p. 148).

Importante nesse processo é a reflexão de Latouche (2009), ao destacar sabiamente, que se trata de revolução, mas também de retrocesso, de inovação, mas também de repetição. Dialeticamente. É a reação ante um sistema devastador ao mesmo tempo em que é o recuo para melhor avançar. É, como bem coloca o autor, sobretudo, resistir. 
Seria utopia pensar em modelos alternativos em um sistema que rejeita outras racionalidades? Sim, mas é uma utopia concreta que se configura em fonte de esperança e sonho ao considerar o real e explorar suas possibilidades (LATOUCHE, 2009). Assim como Latouche (2009), Fernandes (2019) também se baseia no conceito de Ernst Bloch, no qual afirma que a utopia "não é o mesmo que um sonho ou uma esperança desengajada, e sim o fruto de uma posição dialética entre a esperança e a escuridão" (FERNANDES, 2019, p. 51). Portanto, a utopia não é aquilo que é impossível, mas sim o não-lugar. É aquilo que, segundo Fernandes (2019), não tem lugar em nossa sociedade, mas que nos move para a construção do lugar.

Os movimentos aqui destacados se configuram em projetos políticos de construção. Construção de novos pensamentos, nova consciência, nova cultura, nova sociedade - que chamamos de práxis, atividade prática pensada. A práxis é, conforme Fernandes (2019, p. 55), "a unidade dialética da teoria e prática no movimento da negação, é uma pré-condição para o livre exercício das potencialidades humanas". É a ferramenta fundamental para se pensar em um outro mundo, desejável e necessário. É a transformação da realidade, juntamente com a transformação do pensamento.

Sabe-se que o sistema produtivista capitalista não só esgota as energias do trabalhador, como também as forças da Terra (LOWY, 2015). O que ocorreu no período de quarentena e isolamento social devido ao coronavírus foi, apesar de involuntariamente, um chamado a calmaria. Nesse processo, não só o trabalhador (alguns) conseguiu parar e desfrutar de outras possibilidades em seu tempo livre, inclusive maior tempo com familiares, mas o próprio planeta respirou.

Compreendemos que a proposta na qual defendemos requer mudanças significativas em nosso modo de viver, pensar e fazer política, mas, acreditamos em sua possibilidade de maneira gradativa; quem sabe, o período vivenciado tenha sido o impulso para repensar e iniciar a mudança, um passo rumo ao ecossocialismo ou outras propostas alternativas. Afinal, a utopia é um chamado a mobilização; à luta social e ambiental.

\section{Considerações finais}

Em tempos de crise civilizatória, nos propusemos a pesquisar alternativas para um desenvolvimento mais sustentável, acentuando a necessidade de irromper com o modelo hegemônico, capitalista, neoliberal e, infelizmente, tido como verdade única e inquestionável.

Temos clareza das dificuldades e desafios de se pensar em uma proposta alternativa, além dos limites colocados pelo próprio sistema vigente, mas, também temos convicção da importância do trabalho de base, emergencial para se pensar em utopias a serem testadas, utopias mobilizadoras. 
Com nossos argumentos, buscamos defender a conscientização envolvendo politização, emergencial no modelo que visa o lucro em detrimento da natureza e da própria humanidade, sob o discurso de ordem e progresso. No entanto, vale aqui o questionamento: Progresso rumo ao quê? Para quem?

Além disso, entendemos que o papel do Governo é fundamental nesse processo, que engloba desde investimentos em políticas públicas sociais (Educação Ambiental), como também por meio de leis e regulamentações em favor da produção de produtos mais sustentáveis. No mesmo contexto, promover 0 incentivo ao pequeno produtor de policultura e a produção/consumo de alimentos orgânicos, além de exigir maior responsabilidade ambiental das grandes empresas e latifundiários, ao invés do incentivo fiscal e outros benefícios, como, por exemplo, a liberação de inúmeros pesticidas.

Vale destacar que é preciso maior atenção aos discursos e tendências que enfocam no desenvolvimento para a sustentabilidade e os ideários que subjazem tais discursos, tendo em vista que, em muitos casos, são propostas que se configuram como instrumento de atualização ideológica da hegemonia, camuflando questões de ordem estrutural, sem questionar a lógica produtivista. Um dos exemplos é a ecologia capitalista, que visa apenas minimizar os efeitos tóxicos das suas iniciativas voltadas ao consumo e a extração de recursos naturais não renováveis, subjugando uma ecologia social e ambiental, preocupada com o ideário de um novo sistema de produção, trabalho e consumo, em genuíno equilíbrio com o meio ambiente natural.

Por essa razão, mais do que mudanças tecnológicas visando o desenvolvimento sustentável, ou ações pontuais de preservação e conscientização ecológica, defendemos o desenvolvimento da consciência crítica, que considera a complexidade socioambiental, sobretudo porque os problemas ambientais acontecem como decorrência de práticas sociais.

Temos convicção dos desafios e até mesmo da característica utópica desses e tantos outros movimentos que se configuram em luta contra o poder hegemônico, ainda mais em meio a um mundo que necessita continuar "crescendo". Acentuamos que esses movimentos são processos dialéticos e consideram a complexidade da realidade e das relações socioambientais, portanto, não refutam totalmente a produção, mas, defendem, além de outros aspectos, a produção em escala moderada. São perspectivas que visam uma modalidade diferente de funcionamento da sociedade, o que nos parece urgente se quisermos preservar a humanidade e o Planeta.

Basicamente, enfatizamos, além de outros aspectos fundamentais, a reestruturação do modo de produção e consumo, acentuando a necessidade da realocalização do global para o local, principalmente por meio de projeto político. A realocalização não só é necessária, como é possível e irá garantir as necessidades humanas cotidianas, como também o emprego do trabalhador. É a velha fórmula que se renova: pensar globalmente, agir localmente. 
Percebe-se, diante do caos socioambiental em que nos encontramos e da pandemia que nos forçou a renunciar ao que antes considerávamos indispensável, que a simplicidade voluntária não é de todo modo impossível. Defendemos ao evidenciarmos propostas alternativas ao modelo produtivista e consumista, a opção por um modelo mais sustentável, pelo estilo de vida mais lento, mais leve, o que, de certa forma, ocorreu nesse período de quarentena. Mas, sobretudo, um estilo de vida crítico e consciente, sem deixar de questionar a simplicidade que não é voluntária, mas imposta a milhares de cidadãos que vivem às margens de uma sociedade excludente e desigual.

Portanto, é a aderência à simplicidade voluntária, com consciência política, com participação social na luta e reivindicação por qualidade de vida, direito à alimentação saudável e de qualidade, educação libertadora, dentre outros fatores. O papel social também diz respeito à cooperação, a noção de pertencimento, planetariedade, totalidade. Dividimos a mesma morada, que é a Terra, independente de raça, etnia, gênero e/ou classe social, portanto, a cooperação e reciprocidade são indispensáveis se quisermos manter o planeta funcionando. Afinal, as crises climáticas, bem como, crises epidemiológicas, não obedecem a fronteiras.

Assim sendo, pensar no ecossocialismo e outras propostas alternativas ao modelo vigente, requer o rompimento com as tendências voltadas ao consumo artificial, repensando, sobretudo, quais são nossas necessidades reais, a partir de atividades voltadas para um consumo autolimitado, além de outras propostas visando a preservação da natureza e da própria humanidade, como o uso de energias alternativas e limpas, e a relação harmônica entre os membros da comunidade.

Como sugestão para o modelo de vida no qual nos apoiamos, defendemos, além da mudança no padrão de consumo de objetos triviais, uma transição gradativa e consciente a fim de priorizar os bens essenciais e que não são desfrutados devido ao excesso da carga horária de trabalho, como, por exemplo, maior tempo dedicado aos familiares, leituras, hobbies e pequenos prazeres, não mensuráveis monetariamente. Além disso, a mudança e atenção às interações comunitárias, juntamente com a valorização do pequeno produtor local.

A conscientização, juntamente com projetos políticos sociais, será de fundamental importância para 0 desenvolvimento rumo aos elementos mencionados anteriormente, isso por que, a consciência é a possibilidade do despertar para as grandes ou singelas artimanhas do capital, como por exemplo, as estratégias de marketing penetradas no dia-a-dia do cidadão, incutindo a falsa sensação de que para ser é preciso ter.

É, de certo modo, um convite à escolha pelas relações em detrimento dos produtos. Não negligenciamos a ideia de que os indivíduos necessitam de seus empregos fornecidos pelas grandes empresas para garantir sua sobrevivência. No entanto, propomos a reflexão crítica do que realmente 
necessitamos para essa sobrevivência, tendo em vista que, no atual modelo produtivista, muitas "necessidades" são criadas e impostas ao povo, que, na labuta diária e desgastante, vendem sua mão de obra barata para satisfazer o fetiche estrategicamente pensado no sistema capitalista.

Finalmente, supondo que muitos indivíduos, devido ao isolamento social, abstiveram-se do ato do consumo supérfluo, bem como, das relações com familiares e amigos, do que mais sentiram falta? Eis uma proposição para, quem sabe, futura pesquisa e aprofundamento.

\section{Referências}

ARAÚJO, R.B. Utopia e antiutopia contemporânea: a utopia da cidadania planetária e a antiutopia da sociedade de consumo. Tese (Doutorado em Ciências Sociais) - Pontifícia Universidade Católica de São Paulo, 2008.

BAUMAN, Z. Em busca da política. Rio de Janeiro: Jorge Zahar, 2000

BAUMAN, Z. Modernidade líquida. Rio de Janeiro: Zahar, 2001

BAUMAN, Z. Arte da vida. Rio de janeiro: Jorge Zahar Ed., 2009.

CUADRA, F. de la. Buen Vivir: Una auténtica alternativa post-capitalista?.

Polis, Santiago, n.40. p. 1-11, 2015. Disponível em: $<$ https://journals.openedition.org/polis/10893\#quotation> Acesso em: $10 \mathrm{de}$ mar. de 2020.

FERNANDES, S. Sintomas mórbidos. São Paulo: Autonomia Literária, 2019.

GONÇALVES, L.R.C. GONÇALVES, E. JUNIOR, L.B.O. Determinantes espaciais e socioeconômicos do suicídio no Brasil: uma abordagem regional. Nova Economia, Belo Horizonte, n. 21, v.2, p. 281-316, ago. 2011.

LATOUCHE, S. Pequeno tratado do decrescimento sereno. São Paulo: Editora WMF Martins Fontes, 2009.

LOWY, M. A alternativa ecossocialista. São Paulo: Especial Caros amigos, ed. 073, 2015, p.38-39.

MELO, C. Como o coronavírus vai mudar nossas vidas: dez tendências para o mundo pós-pandemia. El País. São Paulo. 12 de abr. de 2020. Disponível em: $<$ https://brasil.elpais.com/opiniao/2020-04-13/como-o-coronavirus-vai-mudarnossas-vidas-dez-tendencias-para-o-mundo-pos-pandemia.html> Acesso em: 28 de abr. de 2020.

PALLARES-BURKE, M.L.G. Entrevista com Zygmunt Bauman. Revista Tempo Social - USP, São Paulo, v.16, n.1, 2004. Disponível em: $<$ http://www.scielo.br/pdf/ts/v16n1/v16n1a15.pdf > Acesso em: 20 de abr. de 2020. 